\title{
Effect of Landslide Surge on Pile Foundation of Overhead Vertical Wharf
}

\author{
Xiaolong Zhang $\mathbb{D}^{1,2}$ Junshuai $M{ }^{1,}$, Chengzhi Wang $\mathbb{D}^{1}{ }^{1}$ and Duoyin Wang $\mathbb{D}^{1,2}$ \\ ${ }^{1}$ National Engineering Research Center for Inland Waterway Regulation, Chongqing Jiaotong University, \\ Chongqing 400074, China \\ ${ }^{2}$ Key Laboratory of Hydraulic and Waterway Engineering of Ministry of Education, Chongqing Jiaotong University, \\ Chongqing 400074, China \\ Correspondence should be addressed to Duoyin Wang; 631502010327@mails.cqjtu.edu.cn
}

Received 28 April 2020; Revised 31 July 2020; Accepted 25 August 2020; Published 3 September 2020

Academic Editor: Francesco Colangelo

Copyright (c) 2020 Xiaolong Zhang et al. This is an open access article distributed under the Creative Commons Attribution License, which permits unrestricted use, distribution, and reproduction in any medium, provided the original work is properly cited.

\begin{abstract}
Waves generated by landslides into water cause great harm to wharfs. Hence, the surge wave pressure generated by the landslide serves as an important reference for the structural design of wharfs in reservoir areas. In this study, a series of hydraulic model tests were performed to study the energy and wave pressure produced by the surge. According to wave pressure-time curves, the extreme values of sudden transient changes in wave pressure are obtained. The mechanism and influencing factors of surge wave pressure on vertical wharf buildings are expounded. On this basis, a formula to calculate the wave pressure exerted by landslide surge on the pile foundation of an overhead vertical wharf is developed. A large number of experiments show that the empirical formula is in good agreement with the experimental data.
\end{abstract}

\section{Introduction}

The collapse of slopes and waves caused by landslides in reservoir areas may cause great harm to navigation buildings and wharfs and can affect ships passing through these areas, as in the case of the landslide at the Dalivayiang reservoir [1] and the landslide into Daning River in Wushan, Chongqing [2]. Channel type reservoirs are located in semiclosed water areas. Thus, a surge in the channel type reservoir is different from that in an open sea environment. The surge induced by a landslide on the reservoir bank cannot be fully attenuated due to its short propagation distance. When it reaches the nearshore water area, it still has a large standing wave height. The surge carries a large amount of energy, which can overturn ships and impact wharf buildings, thereby posing a serious threat to the infrastructure on the reservoir bank and the safety of local residents [3].

In recent years, it has become a development trend for the construction of river terminals in mountainous areas to ensure that the structure of the overhead vertical wharf is suitable for large water level differences. In the past, researchers [4-6] have studied the safety impact of landslide surges on the channel and wharf structure using physical model experiments. The landslide mass of a mountain river causes a large energy surge in a short time, which can be potentially dangerous to wharf structures. In order to avoid the occurrence of disasters and to reduce the impact of disasters caused by landslide surges in reservoir areas, it is necessary to accurately estimate, in advance, the wave pressure and impact on these structures when a disaster occurs and incorporate the corresponding preventive measures during the structural construction or daily operation of the wharf.

Edward [7] analyzed the motion relationship of landslide objects in two extreme positions, namely, vertical falling and horizontal pushing, and proposed a simple formula that related surge height, water depth, and motion speed. Robert and Wiegel [8] explained the relationship between surge and width, water depth, ferred 
number, and landslide speed using a hydrodynamic model test. Pan [9] proposed an algorithm for surge calculation considering wave reflection and wave superposition. On the basis of Jiazheng's algorithm, the phase difference of waves during propagation was considered by $\mathrm{Ha}$ and $\mathrm{Hu}$ [10], and they proposed a formula for calculating the surge height of each part of the reservoir. Based on a threedimensional model, Dai [11] measured the maximum landslide surge and propagation wave height and calculated and analyzed the landslide movement process, surge height, and propagation law based on the three-dimensional model. Hu [12] studied the influence of slope, effective contact area, and affluent depth of solid flow on the surge characteristics according to the principle of solid flow energy exchange. Huang [13] proposed a calculation model of surge pressure using a physical model and employed the calculation model to analyze and evaluate the safety of a dam under the action of surge.

Although physical block model experiments on landslide surges have provided a considerable amount of research results on wave characteristics, wave propagation, and coastal climbing height [14-22], there are few studies on the relationship between landslide mass and nearby wharf structural pile foundation. In this study, based on a hydraulic physical generalization model test of the Tuokou wharf in Wanzhou Jiangnan of the Three Gorges Reservoir area, the relationship between the landslide and wave pressure acting on the pile foundation of the overhead vertical wharf is analyzed by measuring the wave pressure acting on the pile foundation of the landslide under the action of the surge wave. Furthermore, we analyze and study the relationship between the landslide and wave pressure acting on the pile foundation from various aspects, such as the change characteristics of the diachronic curve, the influencing factors, and the distribution size and propose an empirical formula to characterize the effect of slope and surge on the pile foundation.

\section{Physical Model Experiment}

In this study, the experiment was carried out in a simulated river channel. According to water levels of $145 \mathrm{~m}, 155 \mathrm{~m}$, and $175 \mathrm{~m}$ in the Three Gorges Reservoir area, the experimental water depth was $74 \mathrm{~cm}, 88 \mathrm{~cm}$, and $116 \mathrm{~cm}$ based on a scale of $1: 70$. The wharf structure and the center of the sliding wave body are along the same straight line, and the distance between them is $6.37 \mathrm{~m}$, as shown in Figure 1 .

An overhead vertical wharf model was constructed according to the Jiangnan Tuokou container terminal of Wanzhou port, Chongqing, and the geometric scale was 1 : 70. Fifteen wharf bents were selected. The width of the model was $1.5 \mathrm{~m}$, the design size of the model was $2.28 \mathrm{~cm}$, and the spacing between bends was $10 \mathrm{~cm}$. The wharf model is shown in Figure 2.

There are nine sizes of the simulated landslide mass, of which the width B has three sizes: $0.5 \mathrm{~m}, 1.0 \mathrm{~m}$, and $1.5 \mathrm{~m}$; the thickness $D$ has three dimensions: $0.2 \mathrm{~m}, 0.4 \mathrm{~m}$, and $0.6 \mathrm{~m}$; and the length is $1 \mathrm{~m}$. According to statistical data, the slope angle of the shear outlet of the landslide mass is constrained between $15^{\circ}$ and $60^{\circ}$ with an average value of $33^{\circ}$. Therefore, the slope angles, $\beta$, of the landslide mass in this experiment were designed to be $20^{\circ}, 40^{\circ}$, and $60^{\circ}$. In this test, the front edge of the landslide mass was tangent to the edge of the water surface under different water levels (water depth) and different slope angles, and the sliding distance $L$ of the landslide mass was half the length of the landslide mass, that is, $0.5 \mathrm{~m}$. The landslide model used in the test is shown in Figure 3.

The test conditions were selected according to the water depth, slope, width, and thickness of the slide, thereby totaling 81 groups of test conditions.

Under different landslide conditions, the wave pressure exerted by the landslide surge on the front of the pile foundation of the overhead vertical wharf was measured. Three measuring points were set up under three water levels, and wave pressure tests were performed under a total of 81 groups of testing conditions. The placement of the wave pressure sensor at different water depths is shown in Figure 4. The main measuring equipment was a DH5902 dynamic strain gauge and wave pressure sensor (CYG1145T), as shown in Figure 5.

\section{Experimental Data Analysis}

3.1. Time History Characteristics of Wave Pressure. The change in the wave pressure-time curve at three different measuring points on the same pile is shown in Figure 6.

It can be seen from the figure that the wave pressure-time curve shows a trend of rapid rise to rapid decline and then becomes steady gradually. As the landslide mass enters the water, the water body is subjected to great impact pressure, and the water body climbs along the front edge to form a wave crest. As the landslide continues to slide, the peak value of the wave will reach the highest value until it breaks and flows into the water body. This generates the initial surge forming the first row of regular waves. As the wave climbs, it is blocked by the structure, and the wave reflection and superposition deformation form multiple wave trains, which are all smaller than the first row of regular waves. Therefore, the measured wave pressure value shows a trend of rapid decrease. As the wave propagating to the wharf becomes smaller, the wave pressure exerted on the wharf structure is also significantly reduced.

According to the test data, the surge wave pressure of landslides exhibits a transient mutation, which can be regarded as the most concerned extreme value in engineering.

3.2. Analysis of Wave Pressure Influencing Factors. According to the research of Mohammed et al. [23, 24], the formation mechanism of swell is different from that of wind waves. Wind waves are surface waves directly generated by the action of winds, and their influence range is shallow. Wave energy is concentrated in the upper part of the water body, and its propagation direction is consistent with wind direction at all times. However, landslide swell is caused by a landslide body. The landslide body exchanges energy with the water body, the impact range is deep, and the energy is concentrated in the entire exchanged water body. With increase in propagation distance, the surge is affected by the water viscosity resistance, scattering, and air resistance, and, thus, the energy loss is higher. 


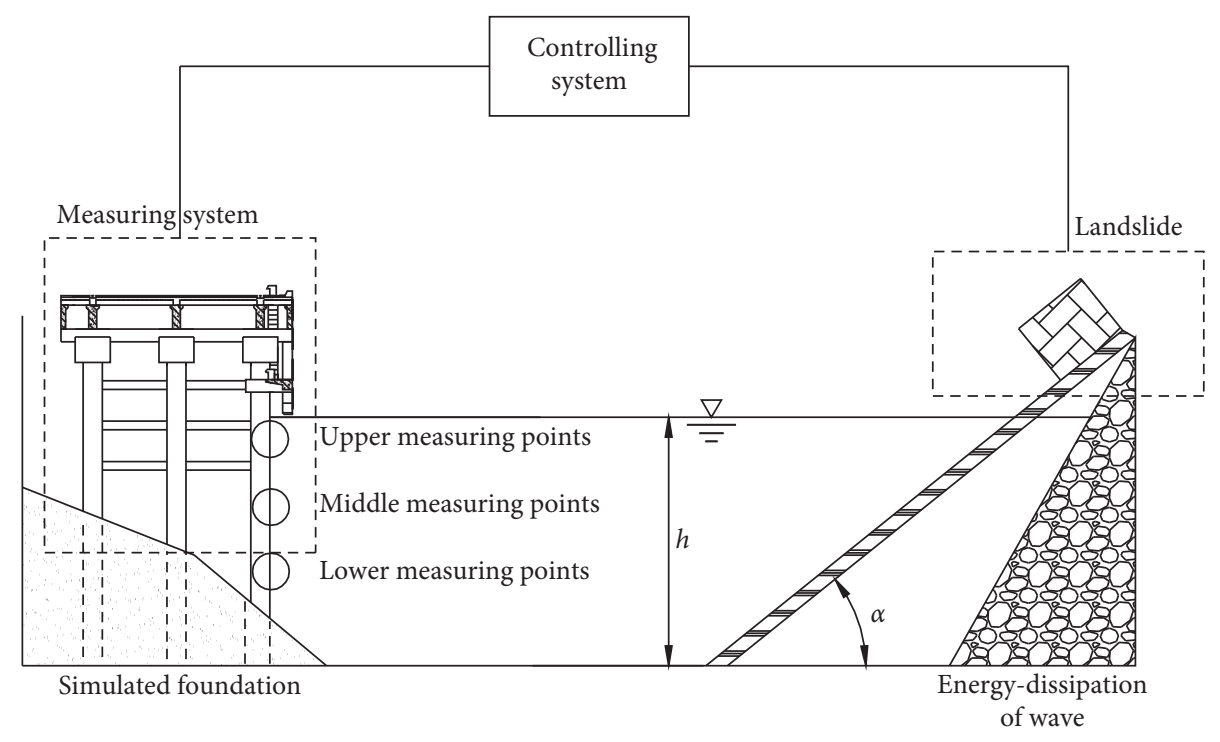

Figure 1: Experimental diagram.

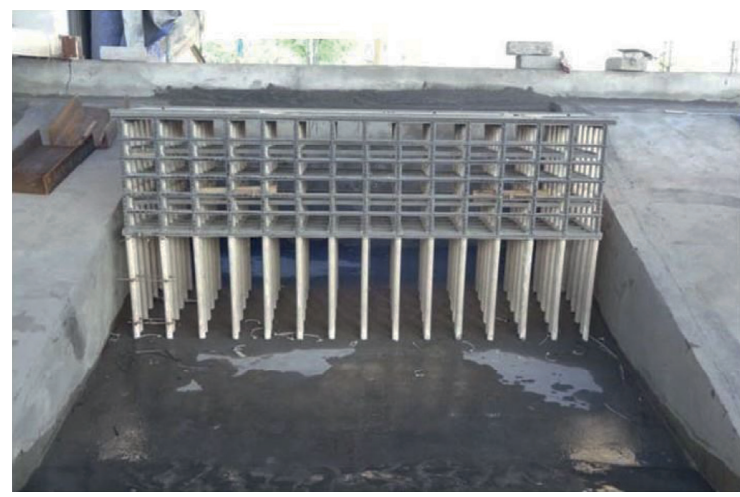

Figure 2: Model of overhead vertical wharf.

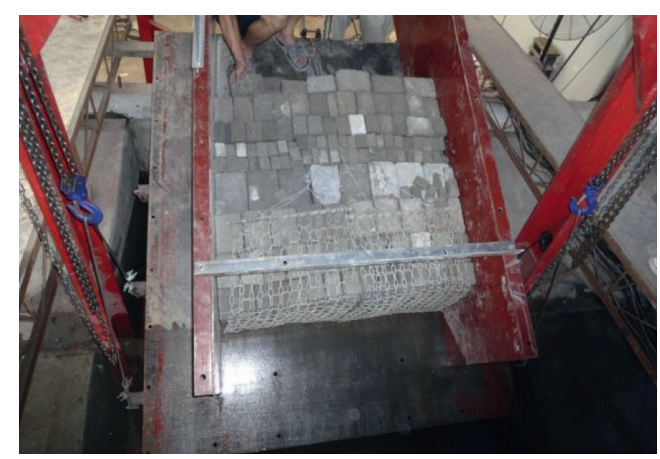

FIgURE 3: Landslide model in test.

The generation of surge is actually the process of energy exchange between the landslide mass and water body. In this test, the landslide mass slides due its own gravity. As the landslide mass enters the water, the gravity potential energy is converted into kinetic energy of the water. The sliding process of the landslide mass can be simplified as shown in Figure 7. obtain $\operatorname{mgl} \sin \alpha=\frac{1}{2} m v^{2}+\operatorname{mgl} \mu \cos \alpha \Rightarrow v^{2}=2 \mathrm{gl}(\sin \alpha-\mu \cos \alpha)$

As the sliding distance $L$ and friction coefficient $\mu$ are constant, the speed of the landslide mass before entering the water is only dependent on the inclination of the sliding surface, and, hence, the speed increases with an increase in the inclination of the sliding surface. Therefore, the energy (i.e., initial kinetic energy) of the landslide mass when entering the water body at the same inclination of the sliding surface is only determined by the volume of the landslide mass.

Three groups of measurement schemes were selected to observe the variation of the initial maximum wave pressure with the landslide volume at the upper, middle, and lower measurement points, as shown in Figures 8-10. It can be seen from the figure that the initial maximum wave pressure increases with the increase of the landslide volume. The initial maximum wave pressure values of the upper, middle, and lower measuring points are consistent with the change of the landslide volume, and the maximum initial wave pressure always appears near the static water surface (upper measuring point).

It can be seen from Figures 11-13 that the initial maximum wave pressure measured at the middle and low water levels is greater than that at the high water level when the landslide volume is the same under the same sliding plane inclination. The main reason for this is that, in the test, the difference between the middle and high water levels is twice that between the middle and low water levels. Hence, unlike that at the high water level, the wave pressure changes at the middle and low water levels are similar. Furthermore, according to the law of conservation of energy, the wave energy formed under the same sliding plane inclination should be the same. When the water level is low, the same amount of energy should be shared within a small volume of water, while when the water level is high, the same amount of energy will be distributed in the larger 


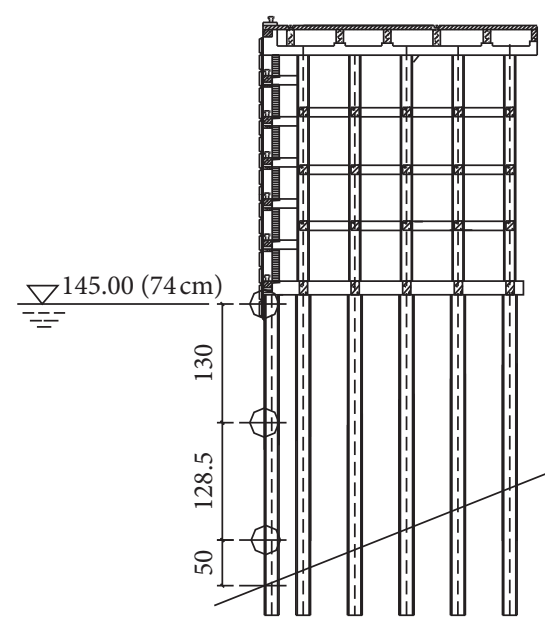

(a)

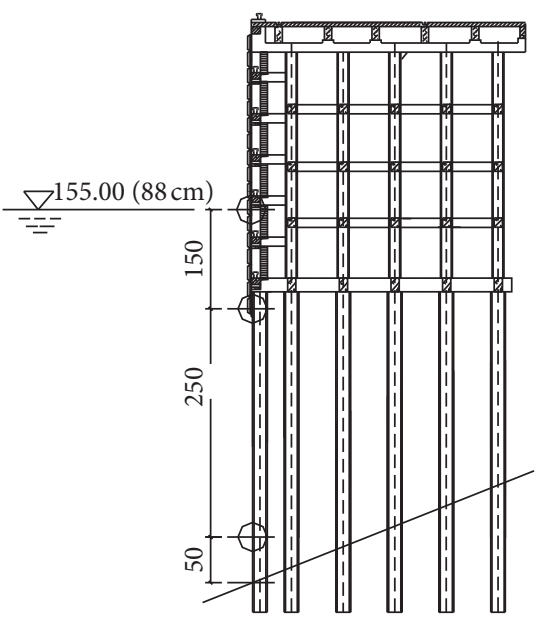

(b)

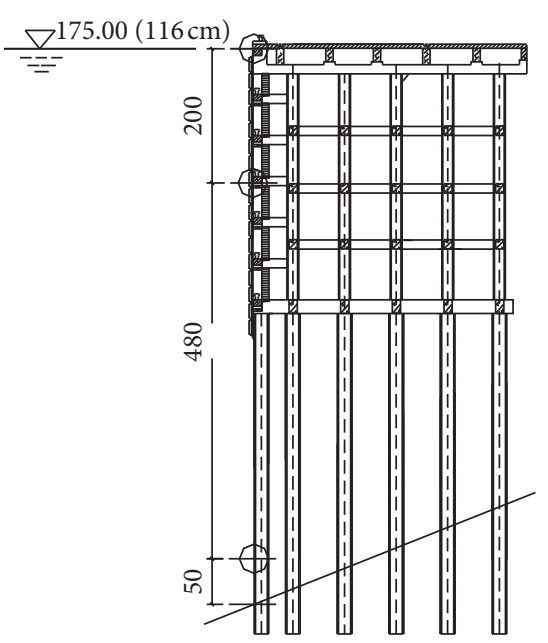

(c)

Figure 4: Side view of the location of wave pressure sensor at (a) $74 \mathrm{~cm}$ water depth, (b) $88 \mathrm{~cm}$ water depth, and (c) $116 \mathrm{~cm}$ water depth.

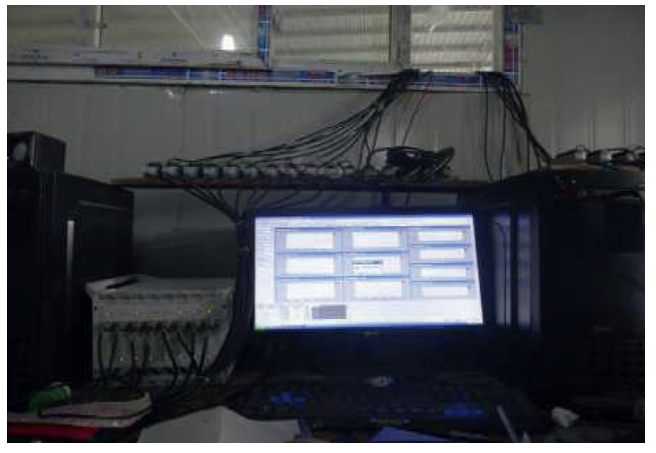

(a)

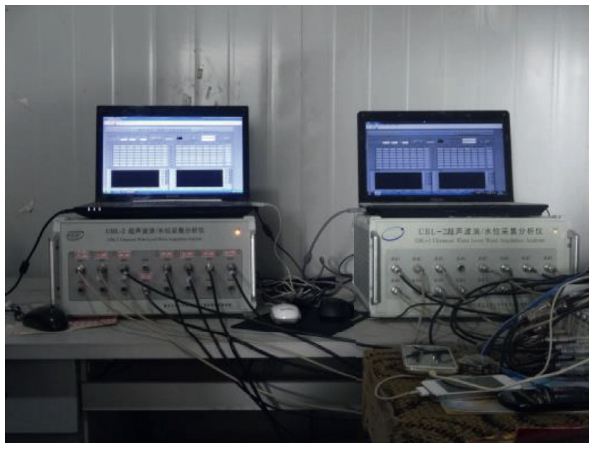

(b)

FIgURE 5: Wave pressure acquisition system in test. (a) Wave pressure acquisition and (b) water level acquisition.

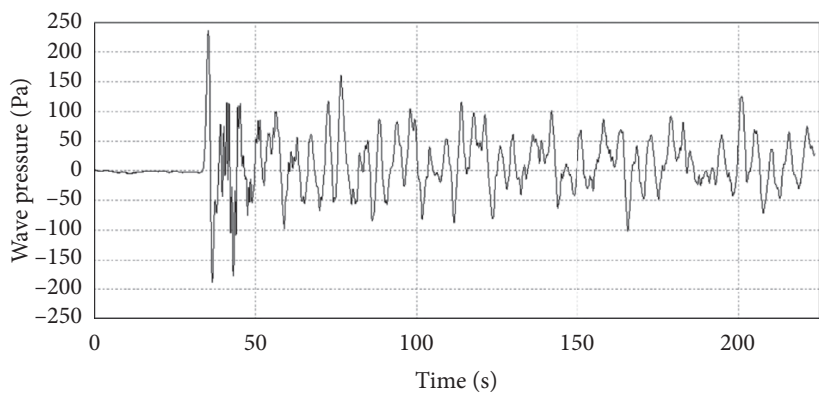

(a)

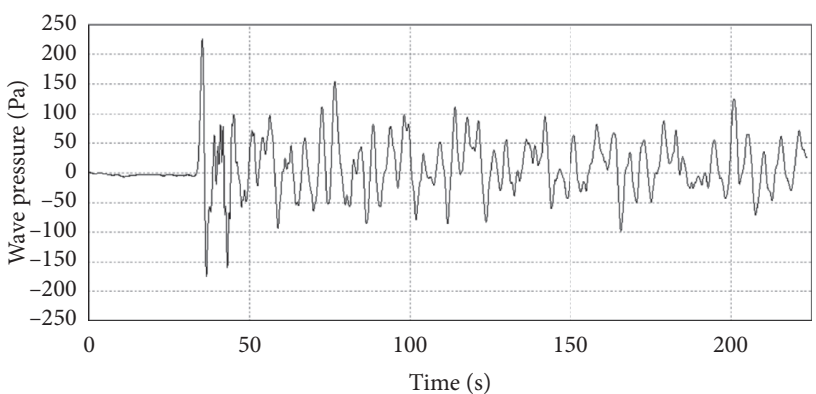

(b)

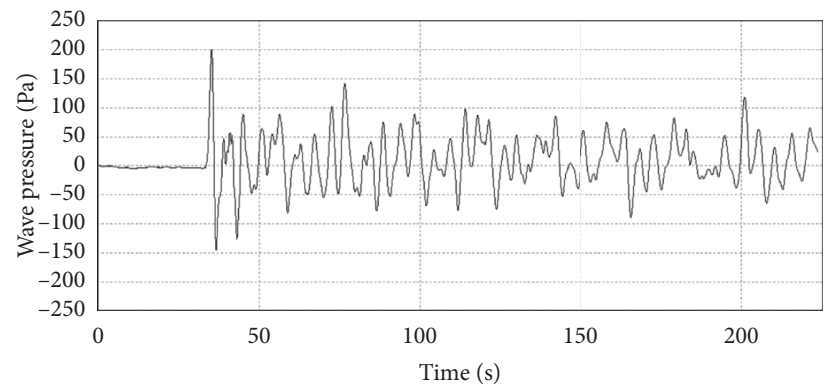

(c)

FiguRE 6: Seventeen wave pressure changes at each measuring point $\left(20^{\circ}, 88 \mathrm{~cm}, 1 \times 1.5 \times 0.4 \mathrm{~m}^{3}\right)$. (a) Upper measuring point. (b) Middle measuring point. (c) Lower measuring point. 


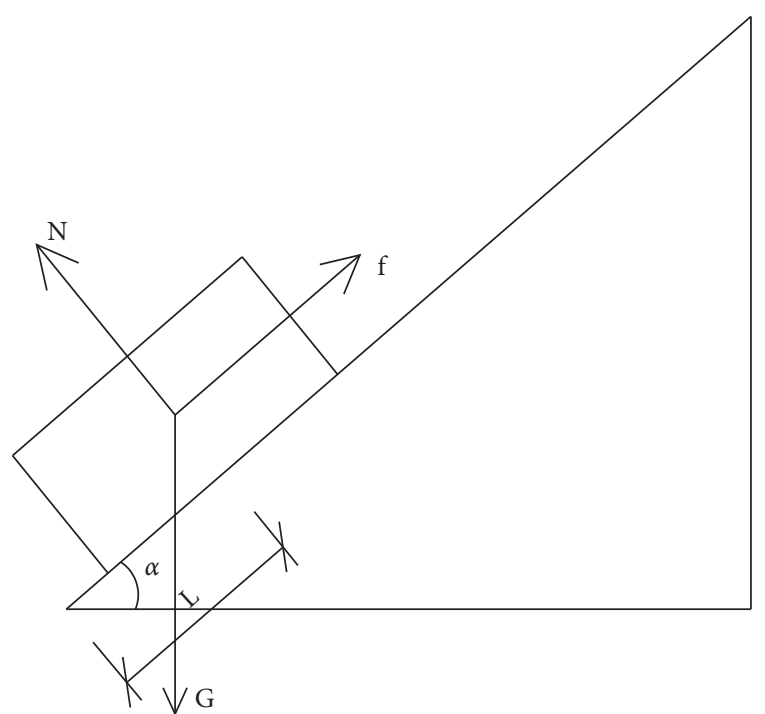

FIgURE 7: Stress diagram of landslide mass.

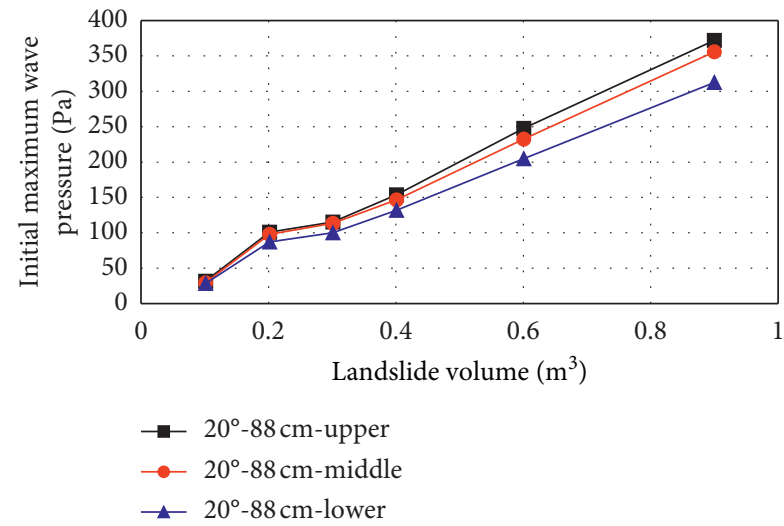

FIgURE 8: Variation of initial maximum wave pressure at upper, middle, and lower measuring points with landslide volume $\left(20^{\circ}, 88 \mathrm{~cm}\right)$.

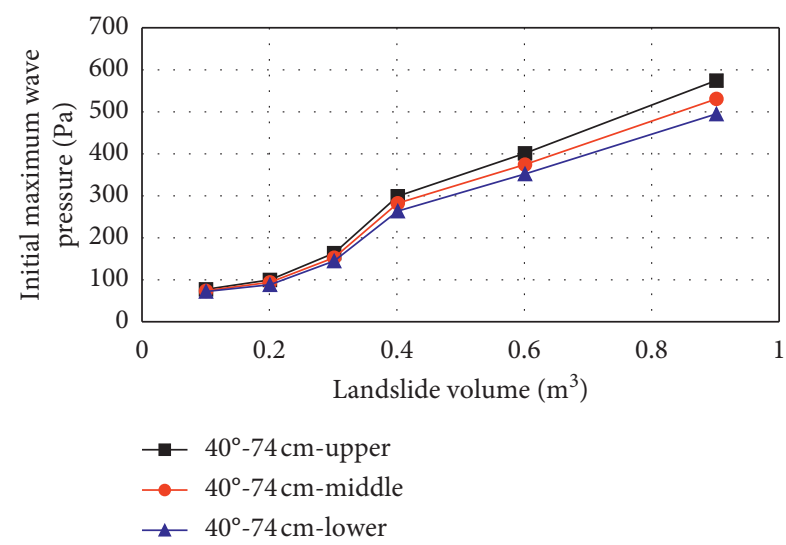

FIGURE 9: Variation of initial maximum wave pressure at upper, middle, and lower measuring points with landslide volume $\left(40^{\circ}, 74 \mathrm{~cm}\right)$.

volume. Therefore, the wave pressure measured at the middle and low water levels is larger than that measured at the high water level.

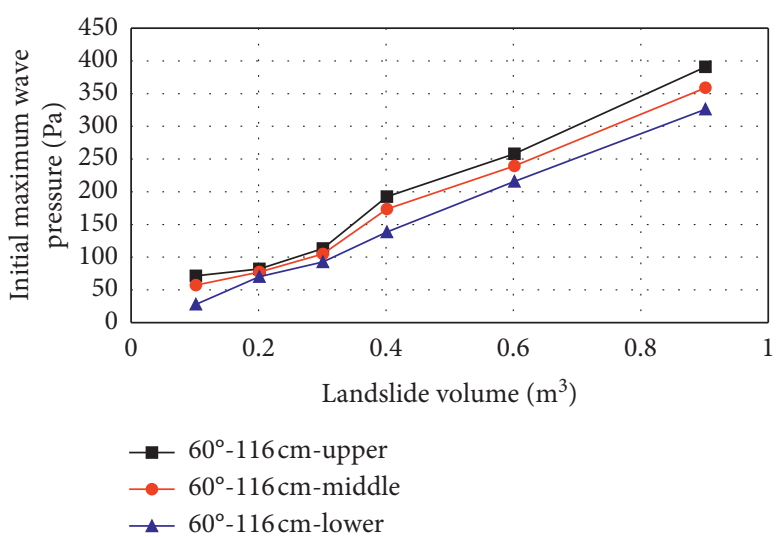

Figure 10: Variation of initial maximum wave pressure at upper, middle, and lower measuring points with landslide volume $\left(60^{\circ}\right.$, $116 \mathrm{~cm}$ ).

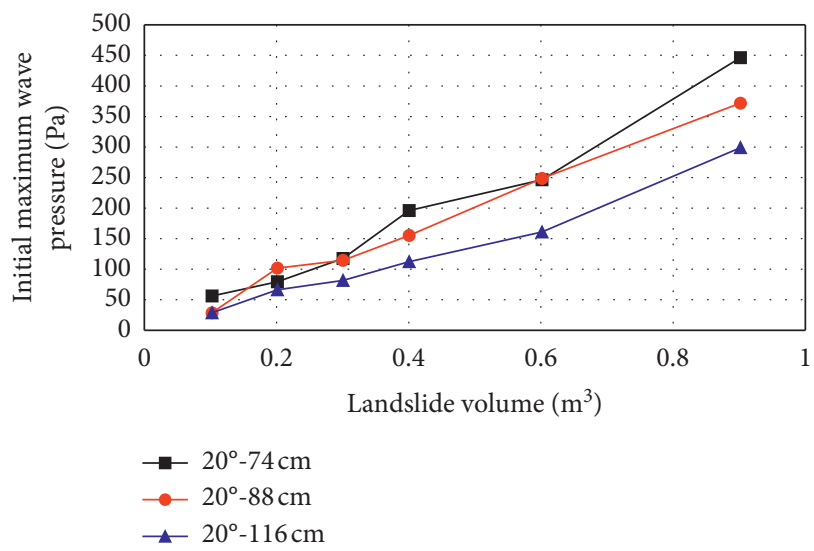

FIgURE 11: Variation of initial maximum wave pressure with landslide volume at three water depths (at $20^{\circ}$ ).

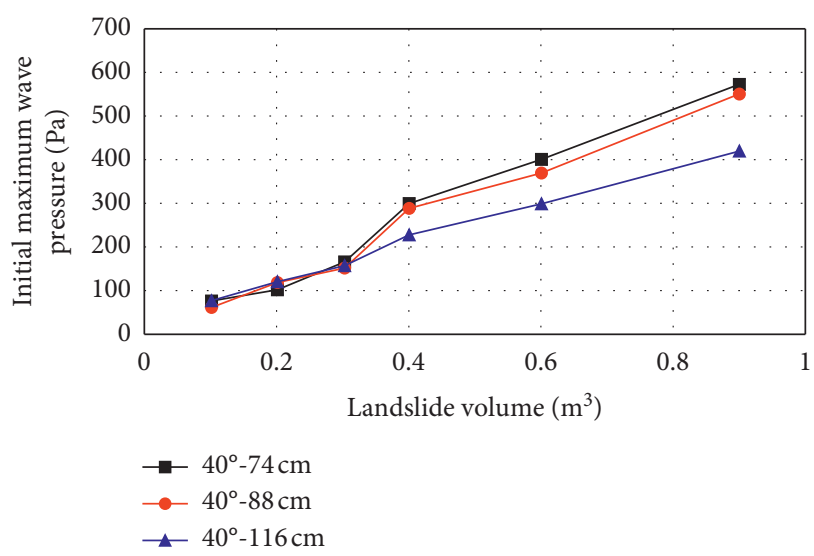

FIgURE 12: Variation of initial maximum wave pressure with landslide volume at three water depths (at $40^{\circ}$ ).

It can be seen from Figures 14-16 that, under the same water level, when the dip angle of the sliding surface is small $\left(20^{\circ}\right)$, the measured initial maximum wave pressure is small. At the middle and low water levels, the maximum initial wave pressure can be obtained at large $\left(60^{\circ}\right)$ and medium $\left(40^{\circ}\right)$ 


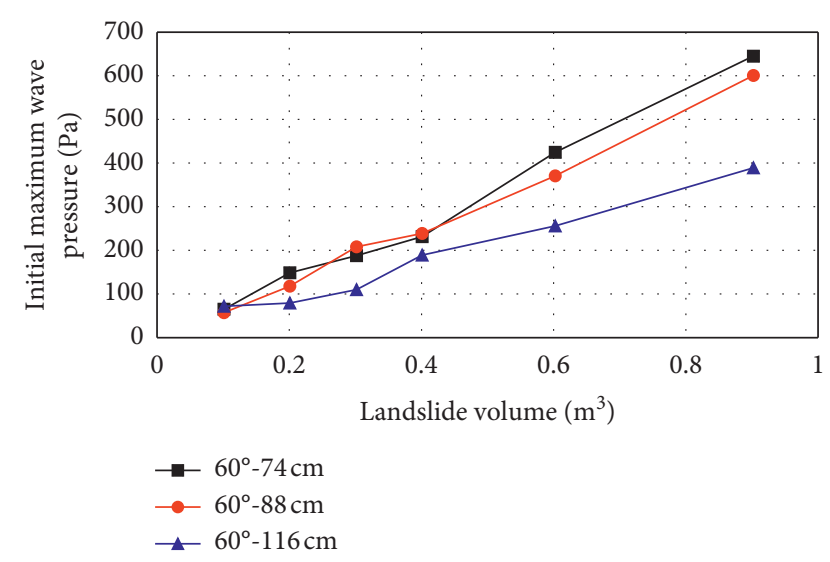

FIgURE 13: Variation of initial maximum wave pressure with landslide volume at three water depths (at $60^{\circ}$ ).

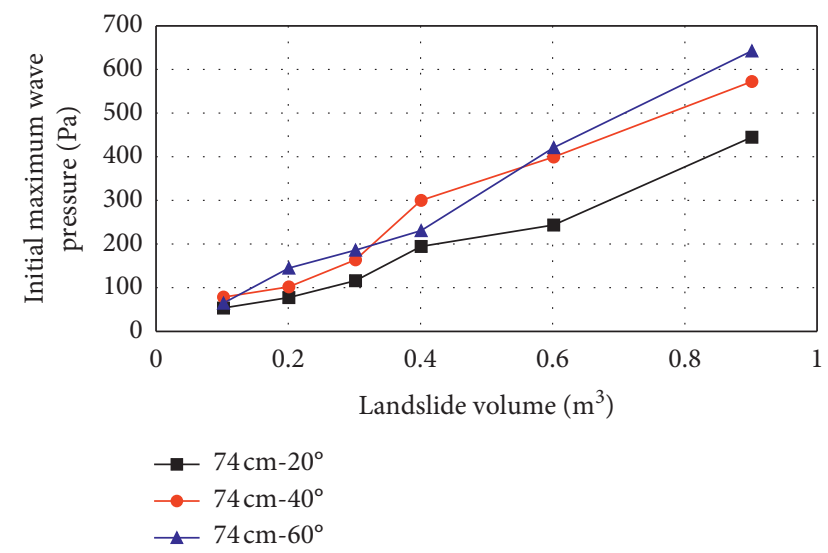

FIGURE 14: Variation of initial maximum wave pressure with landslide volume under different slope angles (at $74 \mathrm{~cm}$ ).

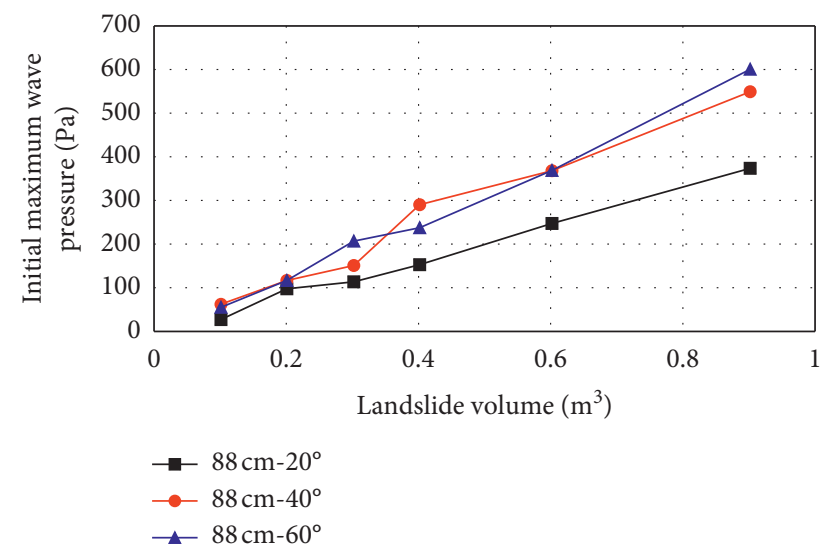

FIGURE 15: Variation of initial maximum wave pressure with landslide volume under different slope angles (at $88 \mathrm{~cm}$ ).

angles; in the high water level, the maximum value of the initial wave pressure is always obtained at $40^{\circ}$. As shown in Figure 17, when the dip angle of the sliding surface, which is directly related to the speed at which the landslide mass enters the water, is small $\left(20^{\circ}\right)$, the energy of the landslide body into the water is small, and the

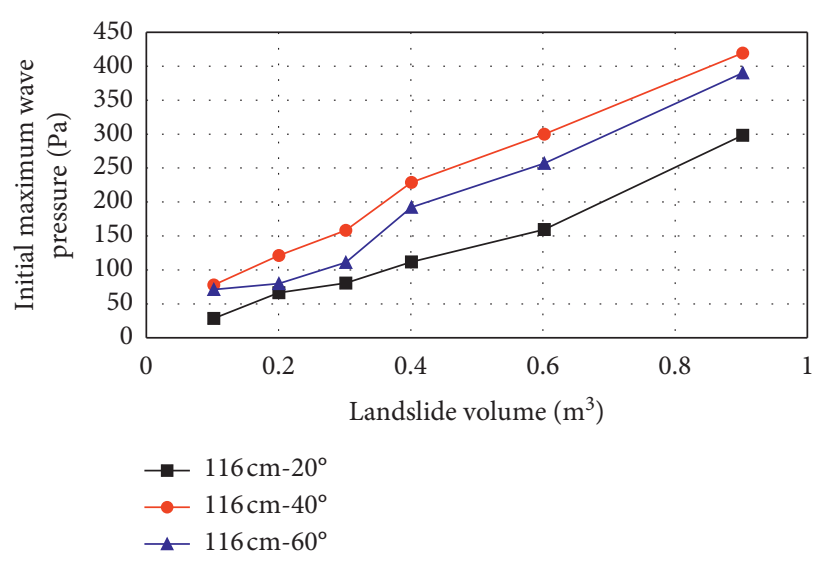

FIgURE 16: Variation of initial maximum wave pressure with landslide volume under different slope angles (at $116 \mathrm{~cm}$ ).

energy exchanged with the water body is also small, so at this time, the initial maximum wave pressure value measured at any water level is obviously small. When the dip angle of the sliding surface is large, the energy of the landslide mass as it enters the water is large. Assuming that the affluent water depth is sufficient at the high water levels and that the thickness of the landslide mass is the same, the contact width between the slope and the water surface is larger when the landslide mass enters the water at $40^{\circ}$ than when it enters the water at $60^{\circ}$. This indirectly reduces the wave propagation distance, and, thus, the initial wave pressure measured at $40^{\circ}$ is larger.

We found that the wave pressure values at the upper, middle, and lower measuring points show a clear decreasing trend, and the initial maximum wave pressure always appears near the static water surface (upper measuring point). Under the static water level, the initial maximum wave pressure intensity of the landslide surge is almost linear along the water depth. Above the static water surface, because the wave height can be taken as the height of the swell center line in front of the wharf structure beyond the static water surface, half of the swell wave height can be taken as the wave pressure distribution height. A simplified calculation model of the initial maximum wave pressure exerted by the landslide surge on the pile foundation of the overhead vertical wharf structure is shown in Figure 18. The wave pressure at the intersection of the pile body and ground, that is, at the pile depth, is determined using the following formula:

$$
P_{d}=k P,
$$

where $K$ is the initial maximum wave pressure reduction coefficient; the value of $K$ is within the ranges of $0.70-0.83$ at the high water level and $0.84-0.89$ at the low water level.

3.3. Formulation. According to the above analysis, the initial maximum wave pressure value $p$ at the water surface is related to the single width volume (width and thickness 


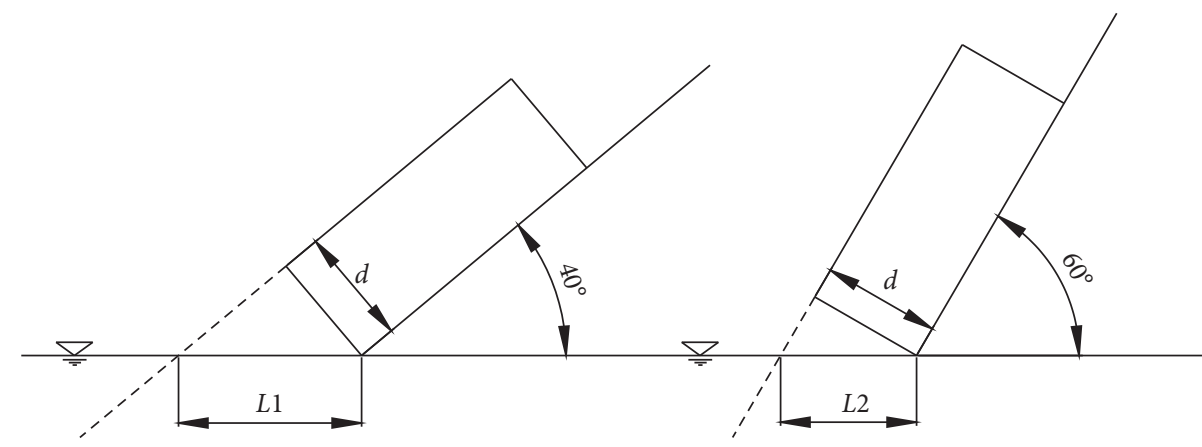

FIGURE 17: Water entry state of landslide mass under different slope angles.

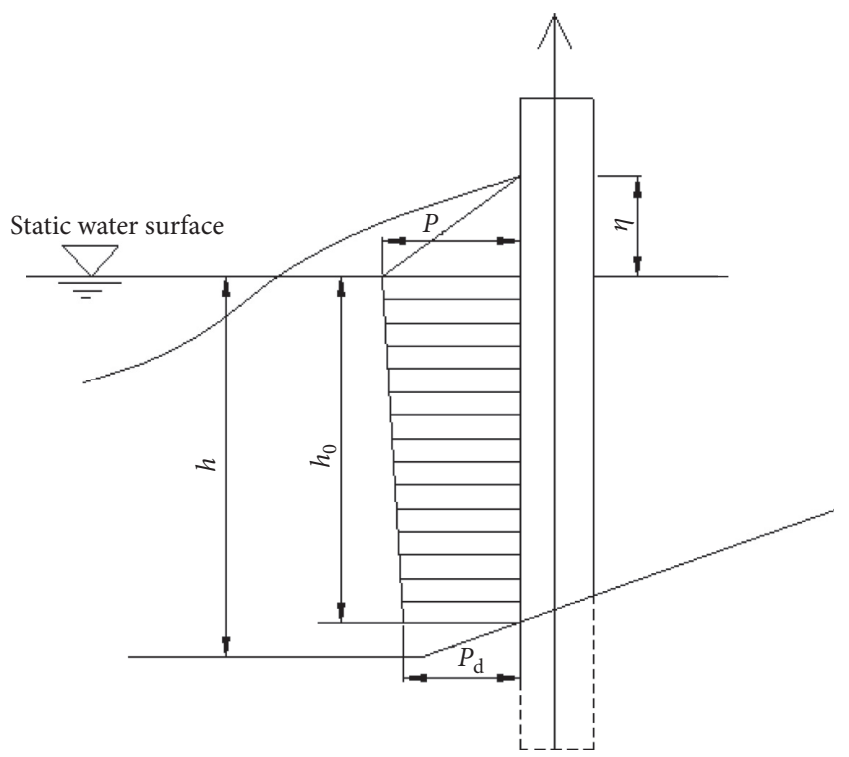

FIGURE 18: Simplified calculation model of landslide surge wave pressure.

change, length is fixed), the angle of the sliding surface $\beta$, the sliding distance $L$, the water depth $h$, and the volume weight $\gamma$ of the water body, which can be obtained by the dimensional analysis method:

$$
f\left\{\frac{P}{\gamma h}, \beta, \frac{l}{d}, \frac{h}{b}\right\}=0 .
$$

Based on the authors' expertise, linear, power, and exponential functions were selected for multiple regression analysis to obtain formulae to estimate the initial maximum wave pressure at the hydrostatic surface. The values of initial maximum wave pressure measure under 81 groups of test conditions were compared with those calculated using these formulae. As shown in Figure 19, the power function formula exhibited a high degree of coincidence between the measured and calculated values:

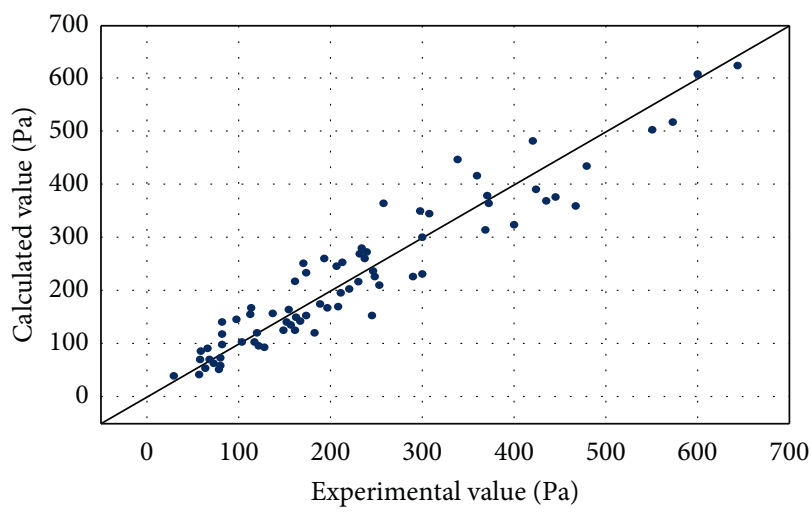

FIgURE 19: Comparison between calculated value and test value.

$$
\frac{P}{\gamma h}=0.032 \beta^{0.464}\left(\frac{l}{d}\right)^{-0.822}\left(\frac{h}{b}\right)^{-1.158} .
$$

\section{Conclusion}

(1) With the slide of landslide, the time curve of wave pressure increases rapidly, decreases rapidly, and then tends to be calm gradually. The transient mutation of the surge wave pressure as the landslide mass enters the water can be regarded as the extremum of engineering concern.

(2) In the process of wave attenuation, the initial maximum wave pressure formed when the initial wave propagates to the wharf structure has the greatest influence on the wharf structure.

(3) The maximum value of the initial wave pressure always appears near the static water surface (upper measuring point), and the value of the initial wave pressure is larger when the landslide mass enters the water at $40^{\circ}$ than that at $20^{\circ}$ and $60^{\circ}$.

(4) Under the static water surface, the positive wave pressure intensity of landslide surge on the vertical pile of overhead vertical wharf is approximately calculated according to the linear distribution. The calculation formula can refer to the empirical 
formula, and the effect of landslide surge should be considered in the design of Wharf in reservoir area.

\section{Data Availability}

The data used to support the findings of this study are available from the corresponding author upon request.

\section{Conflicts of Interest}

The authors declare that they have no conflicts of interest.

\section{Acknowledgments}

The authors would like to acknowledge the financial support from the National Natural Science Foundation of China under Contract no. 51979017.

\section{References}

[1] G. B. Crosta, S. Imposimato, and D. Roddeman, "Landslide spreading impulse water waves and modelling of the vajont rockslide," Rock Mechanics and Rock Engineering, vol. 6, pp. 1-24, 2015.

[2] Z. Y. Cheng, P. Y. Wang, C. Y. Yang, and X. D. Zhou, "Damage characteristics and prevention and control of small and medium-sized ships caused by landslide and surge in mountainous waterway," Water Transport Engineering, vol. 11, pp. 107-113, 2019.

[3] P. Y. Wang, "Study on the mechanism of the influence of landslides and swells on navigation," in Proceedings of the 19th China Ocean (Shore) Engineering Symposium (I), China Ocean Engineering Society: Ocean Engineering Branch of China Ocean society, Jinan, China, pp. 10-19, July 2019.

[4] Y. Q. Men, Study on the Surge Characteristics of Steep Rock Landslides in River Type Reservoirs in Mountainous Areas and its Influence on Navigation Conditions, Chongqing Jiaotong University, Chongqing, China, 2013.

[5] L. Chen, Experimental Study on the Characteristics of Landslide Surge and its Influence on Waterway of River Type Reservoir in Mountainous Area, Chongqing Jiaotong University, Chongqing, China, 2014.

[6] P. Y. Wang, L. F. Han, and T. Yu, "The impact of ship impact force on High Pile Wharf under the action of landslide surge in the three gorges reservoir area," Journal of Harbin University of Engineering, vol. 37, no. 6, pp. 878-884, 2016.

[7] N. Edward, "Water waves generated by landslides," Journal of the Waterways, Harbors and Coastal Engineering Division, vol. 96, no. 4, pp. 835-855, 1970.

[8] L. Robert and K. E. Wiegel, "Water waves generated by landslides in reservoirs," Journal of the Waterways, Harbors and Coastal Engineering Division, vol. 96, no. 2, pp. 307-333, 1970.

[9] J. Z. Pan, Anti Sliding Stability and Landslide Analysis of Buildings, Water Conservancy Press, Beijing, China, 1995.

[10] Q. M. Ha and W. D. Hu, "Calculation of landslide surge in reservoir,” People's Yellow River, vol. 2, pp. 32-38, 1980.

[11] Y. X. Dai, "Calculation method and physical simulation test of landslide surge on reservoir bank," Master's Thesis, Engineering College of China University of Geosciences, Wuhan, China, 2010.
[12] X. W. Hu, "Study on surge characteristics of river type resservoir landslide in mountain area," Master's Thesis, Hehai college, Chongqing Jiaotong University, Chongqing, China, 2010.

[13] J. L. Huang, "Study on the influence of landslide surge on dam body," Doctoral Dissertation, School of construction engineering, Tianjin University, Tianjin, China, 2011.

[14] H. Y. Chen, P. Cui, X. Q. Chen, X. H. Zhu, and G. G. D. Zhou, "Laboratory experiments of water pressure loads acting on a downstream dam caused by ice avalanches," Landslides, vol. 12, no. 6, pp. 1131-1138, 2015.

[15] P. Watts, "Tsunami features of solid block underwater landslides," Journal of Waterway, Port, Coastal, and Ocean Engineering, vol. 126, no. 3, pp. 144-152, 2000.

[16] G. Saelevik, A. Jensen, and G. Pedersen, "Experimental investigation of impact generated tsunami; related to a potential rock slide, Western Norway," Coastal Engineering, vol. 56, no. 9, pp. 897-906, 2009.

[17] V. Heller and J. Spinneken, "Improved landslide-tsunami prediction: effects of block model parameters and slide model," Journal of Geophysical Research: Oceans, vol. 118, no. 3, pp. 1489-1507, 2013.

[18] M. Dirisio, P. Degirolamo, and G. Bellotti, "Landslide-generated tsunamis run up at the coast of a conical island: new physical model experiments," Journal of Geophysical Research: Oceans, vol. 114, no. 1, pp. 66-83, 2009.

[19] A. Panizzo, P. Degirolamo, and A. Petaccia, "Forecasting impulse waves generated by subaerial landslides," Journal of Geophysical Research: Oceans, vol. 110, no. 12, pp. 1-23, 2005.

[20] E. K. Lindstrom, G. K. Pedersen, and A. Jensen, "Experiments on slide generated waves in a 1:500 scale fjord model," Coastal Engineering, vol. 92, no. 4, pp. 12-23, 2014.

[21] A. Romano, M. Dirisio, and G. Bellotti, "Tsunamis generated by landslides at the coast of conical islands: experimental benchmark dataset for mathematical model validation," Landslides, vol. 13, no. 6, pp. 1-15, 2016.

[22] S. B. Yue, M. J. Diao, and L. Wang, "Study on initial form and attenuation law of landslide surge," Journal of Water Conservancy, vol. 47, no. 6, pp. 816-825, 2016.

[23] F. Mohammed and H. M. Fritz, "Physical modeling of tsunamis generated by three-dimensional deformable granular landslides," Journal of Geophysical Research-Oceans, vol. 118, no. 16, pp. 3221-3241, 2013.

[24] W. Wang, G. Q. Chen, and K. L. Yin, "Modelings of landslide generated impulsive waves considering complex topography in reservoir area," Environmental Earth Sciences, vol. 75, no. 5, pp. 372-380, 2016. 